\title{
Exploration of CCD-based ICP-AES for Studying Spectral Interferences of Uranium on Other Analytes
}

\author{
Arijit Sengupta*, V.C. Adya, T.K. Seshagiri, and S.V. Godbole \\ Bhabha Atomic Research Centre \\ Trombay, Mumbai, India
}

\begin{abstract}
Even though inductively coupled plasma atomic emission spectrometry (ICP-AES) is a simultaneous multi-elemental analytical technique with improved precision and detection limits and is routinely used for the determination of trace metallic constituents in nuclear fuels and associated materials, it suffers from severe spectral interferences. Due to the multi-electronic nature, uranium has line-rich emission spectra which interfere with the determination of trace metallic constituents in a uranium matrix. Therefore, chemical separation of uranium, followed by the determination of trace metallic impurities in the raffinate by ICP-AES, is generally the adopted procedure by the nuclear industry. Since good resolution is one of the governing factors for reducing spectral interferences, the analysis depends on the resolution of the instrument and the availability of alternative analytical lines for
\end{abstract}

minimizing these spectral interferences. Since a charge-coupled detector (CCD) consists of an array of pixels, it has more options in choosing alternative analytical lines in comparison to the photomultiplier tube-based ICP-AES using a polychromator. On the other hand, a monochromator has the option of choosing alternative lines but, unfortunately, requires a great deal of time to scan all the elements and also requires a large sample size. Therefore, an attempt was made to study the spectral interferences of uranium on different analytical lines for 16 analytes (Ag, B, Ca, Cd, Co, Cr, Cu, Dy, $\mathrm{Eu}, \mathrm{Fe}, \mathrm{Gd}, \mathrm{Mn}, \mathrm{Na}, \mathrm{Ni}, \mathrm{Sm}, \mathrm{Zn}$ ) together with evaluating the correction factors (wherever necessary) using the CCD-based ICP-AES technique. The sensitivity and detection limits of the analytical channels of the elements in the presence of a uranium matrix were calculated. The present study also identified suitable analytical lines of uranium and measured their detection limits.

\section{INTRODUCTION}

To achieve the desired burn-up and maximize the life span of the fuel in the nuclear reactor, it has to go through stringent physical and chemical quality control and quality assurance measurements at each step of the fuel fabrication. Trace metallic impurity analysis is one of the prime steps for chemical quality control of nuclear fuels and associated materials (1-21). Due to

*Corressponding autbor

E-mail: arijita@barc.gov.in the high neutron absorption crosssection of rare earth elements, they have stringent specification limits, while the presence of other elements beyond the specification limits changes the metallurgical properties of fuel materials. Uranium metal and in oxide form is one of the key materials used in the nuclear industry. For that reason, it is required to develop an analytical method for the determination of trace metallic constituents in a uranium matrix. Due to its line-rich emission spectra, the presence of uranium can lead to the over-esti- mation of analytes due to its spectral interferences. Thus, for the determination of trace metallic constituents in a uranium matrix, it either has to be separated physically from the trace metals using the d.c. arc carrier distillation technique or chemical separation, followed by ICP-AES analysis of the raffinate.

The d.c. arc technique, even though the contamination from sample handling is less, suffers from poor precision (10-13). With ICPAES using chemical separation of the major matrix components, the chances of contamination during sample preparation is high but the detection limits and precision are much better. In ICP-AES it is also required to get suitable amounts of extractant and feed conditioning so that there is preferential extraction of the major matrices without loss of the analytes even at trace levels $(2,3,7,8,14-21)$. Therefore, it is required to develop an ICP-AESbased method where sample handling is minimized and the analytical performance of the method (precision, detection limits, linear dynamic range, sensitivity, etc.) is superior.

In the present study, a chargecoupled device (CCD) detector was used to study the spectral interferences of uranium on other analytes. Due to the design of array pixels in the CCD-based detector, the choice of alternative interference-free analytical lines is similar to a photomultiplier-based detector system. Suitable analytical lines for 16 analytes were chosen and the tolerance limit of uranium on different analytical channels of the analytes were determined, together with the 
detection limits and the sensitivity of the analytical lines in the presence of the uranium matrix.

A suitable analytical method was also developed for the determination of uranium by ICP-AES. Four different analytical lines of uranium $(385.958$ nm, 409.014 nm, 367.007 $\mathrm{nm}, 279.394 \mathrm{~nm}$ ) were identified and calibration curves established up to $1000 \mu \mathrm{g} / \mathrm{mL}$ of uranium. The detection limits and sensitivity of the above-mentioned analytical lines of uranium were evaluated. It was found that the detection limits of $409.014 \mathrm{~nm}$ and $385.958 \mathrm{~nm}$ were comparable $(0.09 \mu \mathrm{g} / \mathrm{mL}$ and $0.02 \mu \mathrm{g} / \mathrm{mL}$, respectively), while those of $367.007 \mathrm{~nm}$ and $279.394 \mathrm{~nm}$ were a magnitude of order higher $(0.129 \mu \mathrm{g} / \mathrm{mL}$ and $0.341 \mu \mathrm{g} / \mathrm{mL}$, respectively).

\section{EXPERIMENTAL}

\section{Instrumentation}

The analytical experiments were carried out using a computercontrolled, high resolution, simultaneous atomic emission spectrometer (Spectro Arcos, Germany) with ICP and DC arc as the excitation sources and a charge-coupled device (CCD) as the detector. The instrumental specifications and experimental parameters are summarized in Table I. The detector system, consisting of linear arrays of the CCD detectors (3648 pixels/ array), thermally stabilized together with an optical system, provides the ability to choose alternative analytical lines. In Figure 1, the crosssectional view of the detector system is shown.

\section{Reagents and Standard Solutions}

Rare earth element (REE) and other common impurity standard solutions were prepared from CertiPUR ${ }^{\circledR}$ ICP multi-standard solutions (E. Merck, Darmstadt, Germany) by proper dilution with $0.5 \mathrm{M} \mathrm{HNO}_{3}$. Suprapur ${ }^{\circledR} \mathrm{HNO}_{3}$ and
TABLE I

Instrumental Operating Conditions of ICP-AES

\begin{tabular}{ll}
\hline \multicolumn{2}{l}{ Instrumental Specifications } \\
\hline Optical design & Paschen-Runge mounting, circular design \\
Grating & Holographic \\
Groove density & 1800 grooves/mm (1), 3600 grooves/mm (2) \\
Wavelength range & $130-800 \mathrm{~nm}$ \\
Entrance slit width & 15 microns \\
Resolution (FWHM) & $0.01 \mathrm{~nm}$ from $130-450 \mathrm{~nm}$ \\
& $0.02 \mathrm{~nm}$ from $450-800 \mathrm{~nm}$ \\
Thermal regulation & Controlled to $30 \pm 1{ }^{\circ} \mathrm{C}$ \\
Frequency & 27.12 MHz \\
Pump & Dual channel peristaltic pump \\
Detector & Linear arrays of CCD (3648 pixels/array) \\
Nebulizer & Concentric nebulizer with cyclonic spray chamber \\
ICP torch & Demountable, radial view \\
\hline Operating Conditions & \\
\hline Coolant flow & $6 \mathrm{~L} / \mathrm{min}$ \\
Auxiliary flow & $0.6 \mathrm{~L} / \mathrm{min}$ \\
Total measurement time & $28 \mathrm{~s}$ \\
Pump speed & $30 \mathrm{rpm}$ \\
RF power out put & $0.8-1.5 \mathrm{~kW}$ \\
Input power & $230 \mathrm{~V}$ AC \\
\hline & \\
\hline
\end{tabular}

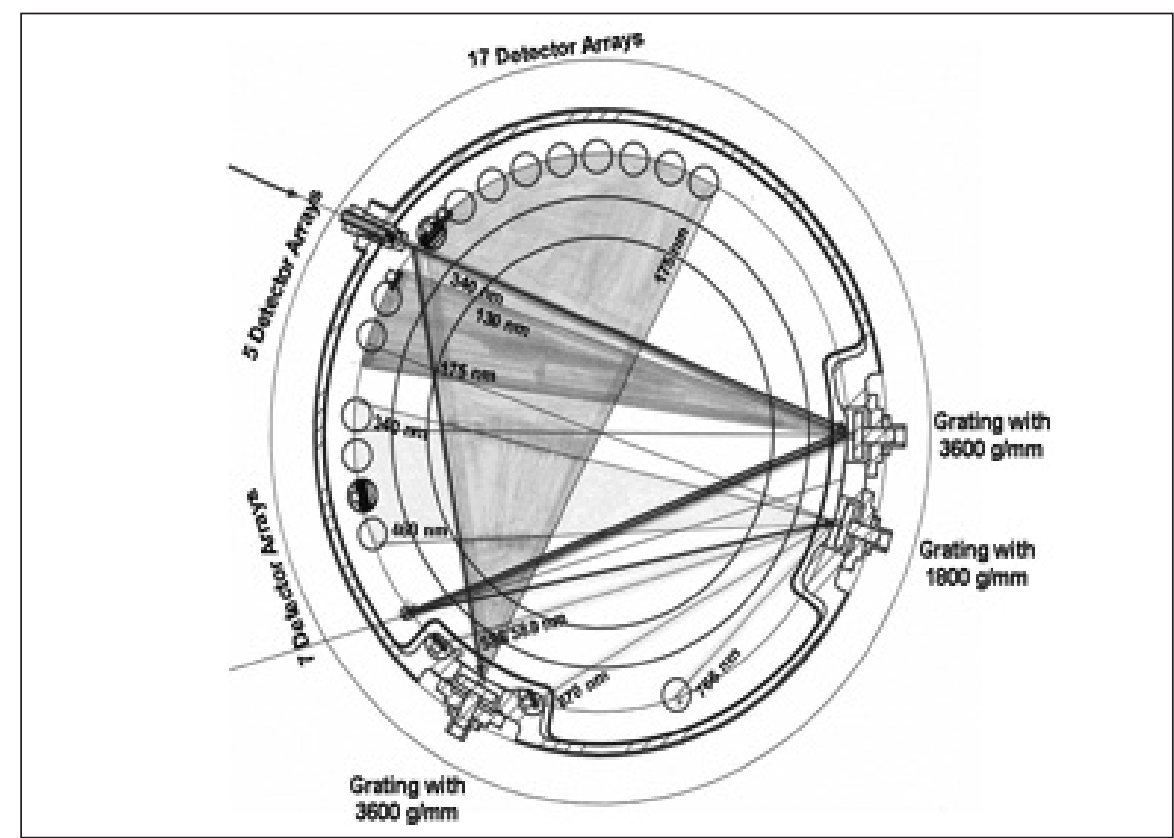

Fig. 1. Cross-sectional view of the array of pixels in CCD-based detector. 
quartz double-distilled water (E. Merck, Darmstadt, Germany) were used for all of the experiments. Multi-point standardization was carried out using $0.5 \mathrm{M} \mathrm{HNO}_{3}$ for the blank and $0.05-1000 \mu \mathrm{g} / \mathrm{mL}$ of the corresponding elemental standard for each analytical line after proper peak search. For the preparation of the uranium stock solution, high purity uranium oxide was used. From the stock solutions, different concentrations of $U$ in the range of $0.05-1000 \mu \mathrm{g} / \mathrm{mL}$ were prepared using proper dilutions with $0.5 \mathrm{M}$ $\mathrm{HNO}_{3}$. Blank correction was carried out using $0.5 \mathrm{M} \mathrm{HNO}_{3}$.

To understand the spectral interference of uranium on other analytes, pure uranium solutions of different concentrations were used, and the contributions at each analytical channel were monitored.

\section{RESULTS AND DISCUSSION}

\section{ICP-AES Determination of Uranium}

Uranium is a multi-electronic element having line-rich emission spectra. Due to the availability of large numbers of emission lines, the sensitivity of the lines was found to be less and the detection limits poorer with a PMT-based detection system. Exploring the superior analytical performances of CCD-based detector systems, an analytical method was developed for the determination of uranium by ICP-AES. The study includes identification of suitable analytical lines. Four emission lines of uranium were chosen $(385.958 \mathrm{~nm}$, $409.014 \mathrm{~nm}, 367.007 \mathrm{~nm}$, and $279.394 \mathrm{~nm}$ ), and Table II lists the determination of uranium using these analytical lines. The calibration curves were established using U- blank, U-10 $\mu \mathrm{g} / \mathrm{mL}, \mathrm{U}-20 \mu \mathrm{g} / \mathrm{mL}$, and U-50 $\mu \mathrm{g} / \mathrm{mL}$ solutions. The solutions of known concentrations of $\mathrm{U}$ (i.e., $500 \mu \mathrm{g} / \mathrm{mL}, 1000 \mu \mathrm{g} / \mathrm{mL}$, etc.)

TABLE II

Determination of Uranium by ICP-AES

\begin{tabular}{|c|c|c|c|c|}
\hline $\begin{array}{l}\text { Actual I } \\
\text { U Conc. }\end{array}$ & $385.958 \mathrm{~nm}$ & $409.041 \mathrm{~nm}$ & $367.007 \mathrm{~nm}$ & $\begin{array}{l}\text { ines by ICP-AF } \\
279.394 \mathrm{~nm}\end{array}$ \\
\hline$(\mathrm{mg} / \mathrm{L})$ & $(\mathrm{mg} / \mathrm{L})$ & $(\mathrm{mg} / \mathrm{L})$ & $(\mathrm{mg} / \mathrm{L})$ & $(\mathrm{mg} / \mathrm{L})$ \\
\hline Blank & $\mathrm{BDL}$ & $\mathrm{BDL}$ & $\mathrm{BDL}$ & BDL \\
\hline 0.05 & $0.06 \pm 0.001$ & $\mathrm{BDL}$ & $\mathrm{BDL}$ & $\mathrm{BDL}$ \\
\hline 0.1 & $0.12 \pm 0.002$ & $0.13 \pm 0.002$ & $0.14 \pm 0.001$ & BDL \\
\hline 0.5 & $0.5 \pm 0.01$ & $0.54 \pm 0.004$ & $0.5 \pm 0.004$ & $0.52 \pm 0.005$ \\
\hline 1 & $1.16 \pm 0.03$ & $1.18 \pm 0.04$ & $1.11 \pm 0.04$ & $1.12 \pm 0.03$ \\
\hline 2 & $2.07 \pm 0.01$ & $2.02 \pm 0.03$ & $2.09 \pm 0.03$ & $2.12 \pm 0.07$ \\
\hline 5 & $5.3 \pm 0.04$ & $5.2 \pm 0.07$ & $5.1 \pm 0.07$ & $5.02 \pm 0.03$ \\
\hline 10 & $10.1 \pm 0.03$ & $10.1 \pm 0.04$ & $10.3 \pm 0.03$ & $10.3 \pm 0.2$ \\
\hline 20 & $20.2 \pm 0.3$ & $20.6 \pm 0.3$ & $20.8 \pm 0.4$ & $20.2 \pm 0.6$ \\
\hline 50 & $50.3 \pm 0.9$ & $51.5 \pm 0.4$ & $50.6 \pm 0.6$ & $51.1 \pm 1$ \\
\hline 100 & $101 \pm 2$ & $100 \pm 1$ & $102 \pm 3$ & $101 \pm 7$ \\
\hline 200 & $204 \pm 5$ & $208 \pm 5$ & $201 \pm 6$ & $207 \pm 5$ \\
\hline 500 & $501 \pm 3$ & $503 \pm 9$ & $502 \pm 8$ & $500 \pm 11$ \\
\hline 1000 & $1016 \pm 15$ & $1009 \pm 11$ & $1019 \pm 21$ & $1004 \pm 14$ \\
\hline
\end{tabular}

$\mathrm{BDL}=$ below detection limit.

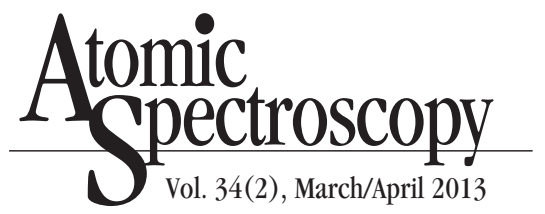

were analyzed using the developed methodology and established calibration curves. The solution containing $1000 \mu \mathrm{g} / \mathrm{mL}$ of $\mathrm{U}$ and using the developed method showed a value of $1000 \mu \mathrm{g} / \mathrm{mL}$ with a relative standard deviation of 5\%. It can, therefore, be concluded that up to $1000 \mu \mathrm{g} / \mathrm{mL}$ the calibration curves maintain linearity. The sensitivity and detection limits of uranium using the above-mentioned analytical lines were evaluated using the slopes of the calibration curves and the concentrations equivalent to the intensity equal to the average of the blank value (15 readings), plus three times the standard deviation of the above measurements, i.e., $x+3 \sigma$. The detection limit of uranium using the $385.958 \mathrm{~nm}$ emission line was found to be the best $(0.02 \mu \mathrm{g} / \mathrm{mL})$, followed by $409.014 \mathrm{~nm}$, while the detection limits using the $367.007 \mathrm{~nm}$ and $279.394 \mathrm{~nm}$ lines were an order of magnitude poorer as shown in Table III.

\section{Spectral Interferences of Uranium on the Analytes}

Interferences may originate at various steps of the ICP-AES sample introduction and excitation process, which convert the sample into atomic radiation. Among various kinds of interferences, spectral interference is significant as far as ICP-AES is concerned. Usually for the determination of a particular analyte at the trace levels in a sample, the most sensitive line is cho-

TABLE III

Determination of Detection Limits of Different Analytical Lines of $\mathbf{U}$

\begin{tabular}{cl}
\hline $\begin{array}{c}\text { Analytical Line } \\
(\mathrm{nm})\end{array}$ & $\begin{array}{c}\text { Detection Limit } \\
(\mathrm{mg} / \mathrm{L})\end{array}$ \\
\hline 279.394 & 0.341 \\
367.007 & 0.1219 \\
385.958 & 0.02 \\
409.014 & 0.09 \\
\hline
\end{tabular}


sen, while if the particular line is overlapped by some other interfering line, an alternate line needs to be selected which may be less sensitive and have poorer detection limits. Improvements in the resolution of the instrument may help to resolve the lines only if spectral overlap is responsible for the interference. If overlap of the lines is from the line-broadening process occurring in the plasma, improvements in instrumental resolution will be insufficient. Therefore, alternate emission lines need to be investigated for their analytical applicability. In some cases it might be that only one analytical line is suitable for analytical purposes. In such cases, appropriate correction factors need to be evaluated.

In the present study, due to the advancement of detector systems, i.e., array of pixels of CCD detectors, the option of choosing an analytical line is better compared to PMT-based detector systems. A detailed study was carried out to choose appropriate emission lines for the trace determination of 16 trace metallic impurities in the presence of a uranium matrix.

Since B, Cd, the rare earth elements, and Ag have stringent specification limits, careful control of these constituents at each step of fuel fabrication is essential. Therefore, it is required to study the spectral interferences of $U$ on the analytical lines of these elements to avoid their overestimation, which is detrimental in qualifying the life span of the fuel rods in the reactor.

Table IV summerizes the contribution of different $U$ concentrations on the different analytical lines of critical elements (Ag, Cd, $\mathrm{Eu}, \mathrm{Sm}, \mathrm{Gd}$, and Dy). In all cases, more than one analytical line was chosen. Since all the analytical lines of a particular element do not suffer from spectral interferences of $U$ to the same extent, the analytical line having lowest contribution from U can be taken as the most suitable analytical line of that particular element in the presence of the U matrix. Table IV shows that the contributions of $U$ on different analytical lines of the analytes vary linearly with the concentration of U. The least interfered analytical lines of the critical elements in the presence of uranium are 338.289 $\mathrm{nm}$ for $\mathrm{Ag}, 182.641 \mathrm{~nm}$ for $\mathrm{B}$, $214.438 \mathrm{~nm}$ for $\mathrm{Cd}, 420.505 \mathrm{~nm}$ for $\mathrm{Eu}, 336.223 \mathrm{~nm}$ for $\mathrm{Gd}, 428.079 \mathrm{~nm}$ for Sm, and $394.468 \mathrm{~nm}$ for Dy. Similarly, Table V summarizes the effect of $U$ concentration on different analytical lines of the common contaminants. A linear increase of U contribution was observed for all the analytical channels with an increase in U concentration. From Table $\mathrm{V}$ the least interfered analytical lines of common metallics were as follows: $588.995 \mathrm{~nm}$ for $\mathrm{Na}$, $393.366 \mathrm{~nm}$ for Ca, $238.204 \mathrm{~nm}$ for Fe, $284.325 \mathrm{~nm}$ for Cr, $269.569 \mathrm{~nm}$ for $\mathrm{Mn}, 221.648 \mathrm{~nm}$ for $\mathrm{Ni}, 224.700$ $\mathrm{nm}$ for $\mathrm{Cu}, 228.616 \mathrm{~nm}$ for $\mathrm{Co}$, and $213.856 \mathrm{~nm}$ for $\mathrm{Zn}$.

The detection limits and the sensitivity for the above-mentioned analytical lines are listed in Table VI. The detection limits were calculated on the basis of the concentration corresponding to $\langle x\rangle+3 \sigma$, where $<x\rangle$ is the average value (15 readings) of the blank intensity, and $\sigma$ is the standard deviation of the above measurements. The sensitivity was calculated based on the emission intensity counts per unit concentration $(\mathrm{mg} / \mathrm{L})$, which is the slope of the calibration curve. Best detection limits can be achieved in the presence of $U$ by using the following analytical lines of the analytes: 338.289 for $\mathrm{Ag}, 182.641 \mathrm{~nm}$ for B, $422.673 \mathrm{~nm}$ for $\mathrm{Ca}, 206.200 \mathrm{~nm}$ for $\mathrm{Zn}, 228.616 \mathrm{~nm}$ for Co, $284.325 \mathrm{~nm}$ for $\mathrm{Cr}, 324.754 \mathrm{~nm}$ for $\mathrm{Cu}, 364.540$ $\mathrm{nm}$ for Dy, $381.967 \mathrm{~nm}$ for $\mathrm{Eu}$, $261.187 \mathrm{~nm}$ for $\mathrm{Fe}, 359.260 \mathrm{~nm}$ for $\mathrm{Sm}, 221.648 \mathrm{~nm}$ for $\mathrm{Ni}, 588.995 \mathrm{~nm}$ for $\mathrm{Na}$, and $257.611 \mathrm{~nm}$ for $\mathrm{Mn}$.
In some situations, the analytical line with lowest detection limit may not be the line with the least spectral interference from U. As indicated above, optimization would then be required to select the best analytical line of a particular element together with acceptable detection limits and minimum spectral interferences.

\section{CONCLUSION}

A systematic study was carried out to understand the spectral interferences of uranium on 16 analytes (Ag, B, Ca, Cd, Co, Cr, Cu, Dy, Eu, Fe, Gd, Mn, Na, Ni, Sm, Zn). For all the analytical lines, the tolerable limits of uranium were evaluated. The detection limits of the analytes were calculated in the presence of the uranium matrix. An analytical method was developed for the determination of uranium by inductively coupled plasma atomic emission spectrometry (ICP-AES), which includes the identification of the emission lines, establishing the calibration curves, and evaluating the sensitivity and detection limits of uranium. For uranium, the $385.958 \mathrm{~nm}$ and 409.014 $\mathrm{nm}$ emission lines were found to be equally sensitive with the detection limits of $0.02 \mu \mathrm{g} / \mathrm{mL}$ and $0.09 \mu \mathrm{g} / \mathrm{mL}$, respectively. Both lines can be used for the determination of uranium by ICP-AES.

Received November 5, 2012 . 


\section{Atomic Spectroscopy \\ $\bigcup$ Vol. 34(2), March/April 2013}

TABLE IV

Spectral Interference of $U$ on the Critical Elements

\begin{tabular}{|c|c|c|c|c|c|c|c|c|c|c|c|}
\hline U Conc. & $\begin{array}{c}B \\
249.773 \\
\end{array}$ & $\begin{array}{c}\text { B } \\
249.677\end{array}$ & $\begin{array}{c}\text { B } \\
182.641 \\
\end{array}$ & $\begin{array}{c}\mathrm{Cd} \\
214.438 \\
\end{array}$ & $\begin{array}{c}\text { Cd } \\
226.502 \\
\end{array}$ & $\begin{array}{c}\text { Cd } \\
361.051 \\
\end{array}$ & $\begin{array}{c}\mathrm{Sm} \\
359.260 \\
\end{array}$ & $\begin{array}{c}\text { Sm } \\
428.079 \\
\end{array}$ & $\begin{array}{c}\text { Dy } \\
353.170 \\
\end{array}$ & $\begin{array}{c}\text { Dy } \\
394.468 \\
\end{array}$ & $\begin{array}{c}\text { Dy } \\
364.540\end{array}$ \\
\hline $\mathrm{mg} / \mathrm{L}$ & $\mathrm{mg} / \mathrm{L}$ & $\mathrm{mg} / \mathrm{L}$ & $\mathrm{mg} / \mathrm{L}$ & $\mathrm{mg} / \mathrm{L}$ & $\mathrm{mg} / \mathrm{L}$ & $\mathrm{mg} / \mathrm{L}$ & $\mathrm{mg} / \mathrm{L}$ & $\mathrm{mg} / \mathrm{L}$ & $\mathrm{mg} / \mathrm{L}$ & $\mathrm{mg} / \mathrm{L}$ & $\mathrm{mg} / \mathrm{L}$ \\
\hline blnk & BDL & BDL & BDL & BDL & BDL & BDL & BDL & BDL & BDL & BDL & $\mathrm{BDL}$ \\
\hline 0.05 & BDL & BDL & BDL & BDL & BDL & BDL & BDL & BDL & BDL & BDL & BDL \\
\hline 0.1 & BDL & BDL & BDL & BDL & BDL & BDL & BDL & BDL & BDL & BDL & BDL \\
\hline 0.5 & BDL & BDL & BDL & BDL & BDL & 0.189 & $\mathrm{BDL}$ & $\mathrm{BDL}$ & $\mathrm{BDL}$ & BDL & $\mathrm{BDL}$ \\
\hline 1 & $\mathrm{BDL}$ & $\mathrm{BDL}$ & $\mathrm{BDL}$ & BDL & BDL & 0.271 & BDL & BDL & BDL & BDL & $\mathrm{BDL}$ \\
\hline 2 & BDL & BDL & BDL & $\mathrm{BDL}$ & BDL & 0.423 & BDL & $\mathrm{BDL}$ & BDL & BDL & 0.01 \\
\hline 5 & BDL & BDL & BDL & BDL & BDL & 0.873 & 0.015 & BDL & BDL & 0.005 & 0.01 \\
\hline 10 & BDL & BDL & BDL & BDL & BDL & 1.709 & 0.026 & 0.031 & 0.004 & 0.014 & 0.02 \\
\hline 20 & BDL & BDL & BDL & BDL & BDL & 3.435 & 0.051 & 0.044 & 0.008 & 0.028 & 0.03 \\
\hline 50 & BDL & BDL & BDL & 0.005 & 0.009 & 8.789 & 0.13 & 0.103 & 0.023 & 0.074 & 0.08 \\
\hline 100 & 0.009 & 0.028 & BDL & 0.008 & 0.016 & 17.557 & 0.264 & 0.192 & 0.047 & 0.148 & 0.17 \\
\hline 200 & 0.03 & 0.064 & $\mathrm{BDL}$ & 0.014 & 0.028 & 34.059 & 0.522 & 0.372 & 0.094 & 0.293 & 0.33 \\
\hline 500 & 0.089 & 0.162 & BDL & 0.031 & 0.056 & 84.656 & 1.296 & 0.799 & 0.238 & 0.722 & 0.77 \\
\hline 1000 & 0.188 & 0.343 & 0.014 & 0.052 & 0.116 & 167.646 & 2.439 & 1.622 & 0.443 & 1.384 & 1.54 \\
\hline U Conc. & $\underbrace{}_{381.967}$ & $\begin{array}{c}\mathrm{Eu} \\
393.048\end{array}$ & $\begin{array}{c}\mathrm{Eu} \\
420.505\end{array}$ & $\begin{array}{l}\text { Ag } \\
328.068\end{array}$ & $\begin{array}{c}\text { Ag } \\
338.289\end{array}$ & $\begin{array}{c}\text { Ag } \\
224.641\end{array}$ & $\begin{array}{c}\text { Gd } \\
335.047\end{array}$ & $\begin{array}{c}\text { Gd } \\
336.223\end{array}$ & $\begin{array}{c}\text { Gd } \\
335.862\end{array}$ & & \\
\hline $\mathrm{mg} / \mathrm{L}$ & $\mathrm{mg} / \mathrm{L}$ & $\mathrm{mg} / \mathrm{L}$ & $\mathrm{mg} / \mathrm{L}$ & $\mathrm{mg} / \mathrm{L}$ & $\mathrm{mg} / \mathrm{L}$ & $\mathrm{mg} / \mathrm{L}$ & $\mathrm{mg} / \mathrm{L}$ & $\mathrm{mg} / \mathrm{L}$ & $\mathrm{mg} / \mathrm{L}$ & & \\
\hline blnk & BDL & BDL & 0.002 & $<0.001$ & $<0.002$ & $<0.123$ & BDL & BDL & BDL & & \\
\hline 0.05 & BDL & BDL & 0.002 & $<0.001$ & $<0.003$ & $<0.112$ & BDL & BDL & BDL & & \\
\hline 0.1 & BDL & BDL & 0.002 & $<0.002$ & $<0.002$ & $<0.140$ & BDL & BDL & BDL & & \\
\hline 0.5 & BDL & BDL & 0.002 & $<0.002$ & 0.004 & $<0.135$ & BDL & BDL & BDL & & \\
\hline 1 & BDL & BDL & 0.002 & $<0.001$ & $<0.004$ & $<0.162$ & BDL & BDL & BDL & & \\
\hline 2 & $\mathrm{BDL}$ & BDL & 0.002 & $<0.003$ & 0.004 & $<0.143$ & BDL & BDL & BDL & & \\
\hline 5 & 0.001 & BDL & 0.003 & 0.006 & 0.008 & $<0.147$ & 0.008 & 0.007 & 0.008 & & \\
\hline 10 & 0.003 & BDL & 0.004 & 0.011 & 0.014 & $<0.176$ & 0.016 & 0.011 & 0.016 & & \\
\hline 20 & 0.005 & BDL & 0.005 & 0.021 & 0.023 & $<0.240$ & 0.03 & 0.019 & 0.036 & & \\
\hline 50 & 0.012 & 0.017 & 0.01 & 0.055 & 0.056 & 0.35 & 0.075 & 0.044 & 0.095 & & \\
\hline 100 & 0.024 & 0.05 & 0.017 & 0.109 & 0.109 & 0.613 & 0.146 & 0.083 & 0.191 & & \\
\hline 200 & 0.047 & 0.11 & 0.031 & 0.217 & 0.211 & 1.062 & 0.289 & 0.162 & 0.384 & & \\
\hline 500 & 0.107 & 0.3 & 0.073 & 0.523 & 0.518 & 2.346 & 0.709 & 0.393 & 0.945 & & \\
\hline 1000 & 0.215 & 0.609 & 0.133 & 1.019 & 0.973 & 3.925 & 1.357 & 0.741 & 1.815 & & \\
\hline
\end{tabular}


TABLE V

Spectral Intereference of U on Common Metallic Constitutents

\begin{tabular}{|c|c|c|c|c|c|c|c|c|c|}
\hline U Conc. & $\begin{array}{c}\mathrm{Cr} \\
205.618\end{array}$ & $\begin{array}{c}\mathrm{Cr} \\
284.325\end{array}$ & $\begin{array}{c}\mathrm{Mn} \\
257.611\end{array}$ & $\begin{array}{c}\mathrm{Mn} \\
260.569\end{array}$ & $\begin{array}{c}\mathrm{Ni} \\
231.604\end{array}$ & $\begin{array}{c}\mathrm{Ni} \\
221.648\end{array}$ & $\begin{array}{c}\mathrm{Ni} \\
227.021\end{array}$ & $\begin{array}{c}\mathrm{Cu} \\
224.700\end{array}$ & $\begin{array}{c}\mathrm{Cu} \\
219.958\end{array}$ \\
\hline $\mathrm{mg} / \mathrm{L}$ & $\mathrm{mg} / \mathrm{L}$ & $\mathrm{mg} / \mathrm{L}$ & $\mathrm{mg} / \mathrm{L}$ & $\mathrm{mg} / \mathrm{L}$ & $\mathrm{mg} / \mathrm{L}$ & $\mathrm{mg} / \mathrm{L}$ & $\mathrm{mg} / \mathrm{L}$ & $\mathrm{mg} / \mathrm{L}$ & $\mathrm{mg} / \mathrm{L}$ \\
\hline 0.05 & BDL & BDL & 0.003 & BDL & BDL & BDL & BDL & BDL & BDL \\
\hline 0.1 & BDL & BDL & 0.003 & BDL & BDL & BDL & BDL & BDL & $\mathrm{BDL}$ \\
\hline 0.5 & BDL & BDL & 0.002 & BDL & BDL & BDL & BDL & BDL & BDL \\
\hline 2 & BDL & 0.007 & 0.002 & $\mathrm{BDL}$ & BDL & BDL & BDL & BDL & BDL \\
\hline 5 & BDL & 0.01 & 0.007 & BDL & $\mathrm{BDL}$ & BDL & BDL & $\mathrm{BDL}$ & BDL \\
\hline 10 & BDL & 0.014 & 0.005 & BDL & BDL & BDL & BDL & BDL & BDL \\
\hline 20 & BDL & 0.023 & 0.005 & BDL & 0.012 & BDL & BDL & BDL & 0.022 \\
\hline 50 & 0.162 & 0.05 & 0.012 & 0.01 & 0.023 & 0.016 & BDL & 0.015 & 0.035 \\
\hline 1000 & 1.66 & 0.899 & 0.163 & 0.123 & 0.33 & 0.227 & 0.612 & 0.141 & 0.357 \\
\hline
\end{tabular}

\begin{tabular}{lcccccccccc} 
U conc & $\mathrm{Co}$ & $\mathrm{Co}$ & $\mathrm{Zn}$ & $\mathrm{Zn}$ & $\mathrm{Na}$ & $\mathrm{Na}$ & $\mathrm{Ca}$ & $\mathrm{Ca}$ & $\mathrm{Fe}$ & $\mathrm{Fe}$ \\
& 228.616 & 230.786 & 213.856 & 206.200 & 589.592 & 588.995 & 396.847 & 393.366 & 239.562 & 238.204 \\
\hline $\mathrm{mg} / \mathrm{L}$ & $\mathrm{mg} / \mathrm{L}$ & $\mathrm{mg} / \mathrm{L}$ & $\mathrm{mg} / \mathrm{L}$ & $\mathrm{mg} / \mathrm{L}$ & $\mathrm{mg} / \mathrm{L}$ & $\mathrm{mg} / \mathrm{L}$ & $\mathrm{mg} / \mathrm{L}$ & $\mathrm{mg} / \mathrm{L}$ & $\mathrm{mg} / \mathrm{L}$ & $\mathrm{mg} / \mathrm{L}$ \\
\hline $\mathrm{blnk}$ & $\mathrm{BDL}$ & $\mathrm{BDL}$ & $\mathrm{BDL}$ & $\mathrm{BDL}$ & 0.038 & 0.037 & 0.224 & 0.221 & 0.071 & 0.065 \\
0.05 & $\mathrm{BDL}$ & $\mathrm{BDL}$ & $\mathrm{BDL}$ & $\mathrm{BDL}$ & 0.067 & 0.066 & 0.342 & 0.341 & 0.056 & 0.052 \\
0.1 & $\mathrm{BDL}$ & $\mathrm{BDL}$ & $\mathrm{BDL}$ & $\mathrm{BDL}$ & 0.093 & 0.089 & 0.521 & 0.518 & 0.072 & 0.067 \\
0.5 & $\mathrm{BDL}$ & $\mathrm{BDL}$ & $\mathrm{BDL}$ & $\mathrm{BDL}$ & 0.086 & 0.084 & 0.262 & 0.26 & 0.037 & 0.035 \\
1 & $\mathrm{BDL}$ & $\mathrm{BDL}$ & $\mathrm{BDL}$ & $\mathrm{BDL}$ & 0.083 & 0.08 & 0.414 & 0.41 & 0.07 & 0.063 \\
2 & $\mathrm{BDL}$ & $\mathrm{BDL}$ & $\mathrm{BDL}$ & $\mathrm{BDL}$ & 0.035 & 0.032 & 0.198 & 0.191 & 0.027 & 0.025 \\
5 & $\mathrm{BDL}$ & $\mathrm{BDL}$ & $\mathrm{BDL}$ & $\mathrm{BDL}$ & 0.131 & 0.124 & 0.883 & 0.859 & 0.145 & 0.134 \\
10 & $\mathrm{BDL}$ & $\mathrm{BDL}$ & $\mathrm{BDL}$ & $\mathrm{BDL}$ & 0.105 & 0.1 & 0.479 & 0.474 & 0.076 & 0.067 \\
20 & 0.007 & 0.01 & $\mathrm{BDL}$ & $\mathrm{BDL}$ & 0.047 & 0.046 & 0.149 & 0.142 & 0.03 & 0.027 \\
50 & 0.014 & 0.02 & $\mathrm{BDL}$ & 0.01 & 0.104 & 0.098 & 0.458 & 0.454 & 0.072 & 0.063 \\
100 & 0.025 & 0.035 & $\mathrm{BDL}$ & 0.03 & 0.195 & 0.181 & 0.891 & 0.864 & 0.202 & 0.187 \\
200 & 0.046 & 0.064 & $\mathrm{BDL}$ & 0.02 & 0.1 & 0.091 & 0.364 & 0.357 & 0.085 & 0.067 \\
500 & 0.101 & 0.149 & $\mathrm{BDL}$ & 0.05 & 0.146 & 0.133 & 0.257 & 0.245 & 0.119 & 0.079 \\
1000 & 0.205 & 0.293 & 0.032 & 0.09 & 0.306 & 0.277 & 0.516 & 0.491 & 0.24 & 0.177 \\
\hline
\end{tabular}




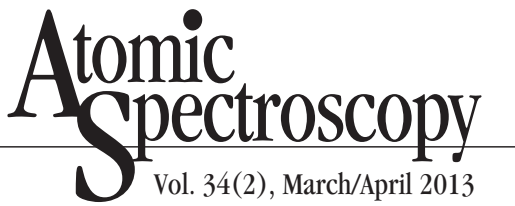

TABLE VI

Determination of Sensitivity and Detection Limits of the Analytes

\begin{tabular}{|c|c|c|c|c|c|c|c|}
\hline Element & $\begin{array}{c}\text { Wavelength } \\
\text { nm }\end{array}$ & $\begin{array}{c}\text { Detection } \\
\text { Limit } \\
\text { mg/L }\end{array}$ & $\begin{array}{c}\text { Sensitivity } \\
\text { Counts } \\
\mathrm{mg} / \mathrm{L}\end{array}$ & Element & $\begin{array}{c}\text { Wavelength } \\
\mathrm{nm}\end{array}$ & $\begin{array}{c}\text { Detection } \\
\text { Limit } \\
\text { mg/L }\end{array}$ & $\begin{array}{c}\text { Sensitivity } \\
\text { Counts } \\
\mathrm{mg} / \mathrm{L}\end{array}$ \\
\hline \multirow[t]{2}{*}{ Ag } & 328.068 & 0.0036 & $5.93 \times 10^{-6}$ & $\mathrm{Eu}$ & 381.967 & 0.00034 & $1.95 \times 10^{-6}$ \\
\hline & 338.289 & 0.0024 & $1.17 \times 10^{-5}$ & & 420.505 & 0.0014 & $2.58 \times 10^{-6}$ \\
\hline \multirow[t]{2}{*}{ B } & 182.641 & 0.0047 & $1.95 \times 10^{-5}$ & $\mathrm{Fe}$ & 239.562 & 0.00407 & $1.76 \times 10^{-5}$ \\
\hline & 249.773 & 0.0051 & $1.255 \times 10^{-5}$ & & 261.187 & 0.0025 & $2.59 \times 10^{-5}$ \\
\hline \multirow[t]{2}{*}{$\mathrm{Ca}$} & 396.847 & 0.00147 & $2.07 \times 10^{-7}$ & $\mathrm{Na}$ & 588.995 & 0.0018 & $1.04 \times 10^{-5}$ \\
\hline & 422.673 & 0.00133 & $1.44 \times 10^{-5}$ & & 589.592 & 0.0025 & $1.92 \times 10^{-5}$ \\
\hline \multirow[t]{2}{*}{$\mathrm{Cd}$} & 214.438 & 0.0036 & $1.29 \times 10^{-5}$ & Mn & 257.611 & 0.00069 & $2.39 \times 10^{-6}$ \\
\hline & 226.502 & 0.00566 & $1.54 \times 10^{-5}$ & & 259.373 & 0.00088 & $2.8 \times 10^{-6}$ \\
\hline \multirow[t]{2}{*}{$\mathrm{Cr}$} & 283.563 & 0.005 & $1.42 \times 10^{-5}$ & $\mathrm{Ni}$ & 221.648 & 0.0077 & $2.02 \times 10^{-5}$ \\
\hline & 284.325 & 0.0037 & $1.58 \times 10^{-5}$ & & 231.604 & 0.0093 & $2.19 \times 10^{-5}$ \\
\hline \multirow[t]{2}{*}{$\mathrm{Cu}$} & 324.754 & 0.0016 & $4.81 \times 10^{-6}$ & $\mathrm{Sm}$ & 359.26 & 0.0032 & $2.35 \times 10^{-5}$ \\
\hline & 327.396 & 0.0048 & $8.81 \times 10^{-6}$ & & 360428 & 0.0045 & $6.18 \times 10^{-5}$ \\
\hline \multirow[t]{4}{*}{ Dy } & 340.78 & 0.0016 & $2.35 \times 10^{-5}$ & $\mathrm{Co}$ & 228.616 & 0.0054 & $1.25 \times 10^{-5}$ \\
\hline & 353.17 & 0.0016 & $4.67 \times 10^{-6}$ & & 238.892 & 0.0056 & $1.49 \times 10^{-5}$ \\
\hline & 364.54 & 0.0011 & $1.35 \times 10^{-5}$ & $\mathrm{Zn}$ & 202.613 & 0.016 & $9.5 \times 10^{-6}$ \\
\hline & & & & & 206.2 & 0.006 & $4.18 \times 10^{-5}$ \\
\hline
\end{tabular}

\section{REFERENCES}

1. K. Bunzl and W. Kracke, J Radioanal. Nucl. Chem. 115(1), 13 (1987).

2. A. Sengupta, V.C. Adya, M. Kumar, S.K. Thulasidas, S.V. Godbole, and V.K. Manchanda, At. Spectrosc. 32, 49 (2011).

3. A. Sengupta, M. J. Kulkarni and, S.V. Godbole, J. Radioanal. Nucl. Chem. 289, 961 (2011).

4. X. Claudon, J.C. Birrolleau, M. Lavergne, B. Miche and C. Bergey, Spectrochim. Acta 42B, 407 (1987).

5. A. Sengupta, B. Rajeswari, R.M. Kadam and R. J. Kshirsagar, J. Radioanal. Nucl. Chem. doi:10.1007/s10967-011-1535-7 (2011).

6. A. Sengupta, B. Rajeswari, R.M. Kadam and R. Acharya, At. Spectrosc. 32(5), 200 (2011).

7. J. N. Mathur, M.S. Murali, P.R Natarajan, L.P. Badheka, A. Banerji, K.M. Micheal, S.C. Kapoor and R.K. Dhuwad, J. Radioanal. Nucl. Chem. 165(4), 219 (1992).
8. Arijit Sengupta, B. Rajeswari, R.M. Kadam and S,V.Godbole, At. Spectrosc. 33(2), 48 (2012).

9. T.G. Bangia, B.A. Dhawale, V.C Adya and M.D. Sastry, Fresenius J. Anal. Chem. 332, 802 (1988).

10. N.K. Porwal, A.A. Argekar, P.J. Pnrohit, A.G. Page, and M.D. Sastry, Fresenius J. Anal. Chem. 338, 255 (1990).

11. A.G. Page, K.H. Madraswala, S.V. Godbole, Madhuri J. Kulkarni, Vanita S. Mallapurkar, and B.D. Joshi, Fresenius Z. Anal. Chem. 315,38 (1983).

12. A.G. Page, S.V. Godbole, S Deshkar, Y. Babu and B.D. Joshi, Fresenius J. Anal .Chem. 287, 304 (1977).

13. A.G.I. Dalvi, C.S. Deodhar, T.K. Seshagiri, M.S. Khalap and B.D. Joshi, Talanta 25, 665 (1978).

14. R.K. Malhotra and $\mathrm{K}$ Satyanarayana, Talanta 50(3), 601(1999)
15. S.G. Johnson, J.J. Giglio, P.S Goodall and D.G. Cummings, Proceedings of SPIE-The International Society for Optical Engineering 3270, 158 (1998).

16. S. Marin, S. Cornejo, C. Jara and N. Duran Fresenius' J. Anal. Chem. 355(5-6), 680 (1996).

17. E.A. Huff, Spectrochim. Acta Part B 42, 275 (1987).

18. P.J. Purohit, N. Goyal, S.K. Thulasidas, A.G. Page and M.D. Sastry, Spectrochim. Acta Part B 55, 1257 (2000).

19. E.A. Huff and D.L. Bowers, Appl. Spectrosc. 43(2), 223 (1989).

20. R. Ko, Appl. Spectrosc. 38(6), 909 (1984).

21. C. Mahan, S. Bonchin, D. Figg, D. Gerth and C. Collier, J. Anal. Spectrom. 15, 929 (2000). 